Buchholz, B. A., Shively, K., Peppler, K. A., \& Wohlwend, K. E. (2014). Hands on, hands off: Gendered access in crafting and electronics practices. Mind, Culture, and Activity, 21(4), 278-297. doi: 10.1080/10749039.2014.939762

\title{
Hands On, Hands Off: \\ Gendered Access in Crafting and Electronics Practices
}

Beth Buchholz , Kate Shively, Kylie Peppler \& Karen Wohlwend

\begin{abstract}
The Maker movement promotes hands-on making, including crafts, robotics, and computing. The movement's potential to transform education rests in our ability to address notable gender disparities, particularly in STEM fields. E-textiles-the first femaledominated computing community-provide inspiration for overcoming longstanding cultural divides in classrooms. Analysis of children's use of e-textiles reveals that materials like needles, fabric, and conductive thread rupture traditional gender scripts around electronics and implicitly gives girls hands-on access and leadership roles. This reconceptualization of cultural divides as sets of tacitly accepted practices rooted in gendered histories has implications for reconceptualizing traditionally male-dominated areas of schooling.
\end{abstract}




\section{Hands On, Hands Off: \\ Gendered Access in Crafting and Electronics Practices}

The contemporary Maker movement and the broader "Do-It-Yourself" (DIY) culture celebrates innovation, creativity, and community engagement across a wide array of genres (e.g., cooking, sewing, woodcrafts, robotics) but unified by a common commitment to open exploration, intrinsic interest, and creative ideas. The movement is now increasingly spreading across online communities, physical spaces, and even annual events like Maker Faires, which are popping up all over the world (Dougherty, 2013). Moreover, there is growing national recognition of the Maker Movement's potential to transform education (Kalil, 2010; White House, 2009). However, the movement's potential to transform education rests in our ability to address notable gender disparities, particularly in STEM fields. This is particularly true of electronics, engineering, and robotics activities with predominant appeal to male users. For example, a review of Arduino, a popular robotics toolkit, revealed female designers constituted less than one percent of users (Buechley \& Mako-Hill, 2010). By contrast, crafting, sewing, and other textile design communities attract disproportionate numbers of girls and women (Buechley, 2013).

Seeking to bridge this gender divide, several leading designers created alternative materials that integrate electronics and crafting resulting in new kinds of toolkits and activities, including:

- paper computing: paper, conductive paint and electronics (Qi \& Buechley, 2010), 
- squishy circuits: conductive play-doh and electronics Johnson \& Thomas, 2010), as well as

- e-textiles: fabric artifacts that include embedded computers and other electronics (Berzowska, 2005; Marculescu et al., 2003)

E-textiles, perhaps the most well-studied of these innovations (Buechley, Peppler, Eisenberg, \& Kafai, 2013), emerged as the first-ever female-dominated computing field; over $60 \%$ of e-textile designers in the wild are women (Buechley, 2013). It is important to note that these designers used the LilyPad Arduino, a tool closely related to the Arduino mentioned above with the same hardware and programmed by the same software. The two only differ slightly in their designs, modifications to the LilyPad Arduino enable it to be easily sewn into clothing or other textile garments. This small difference means vastly different things for the practices privileged in maker activities (i.e., sewing instead of soldering a circuit) as well as the products produced (i.e., electronically-enhanced high-end fashion as opposed to robots).

Building on these findings for e-textiles' early promise to dramatically shift cultural divides in the wild (i.e., in Maker or DIY communities), we explored how such alternative tools and materials are taken up in classrooms and the resulting impact of their associated gendered practices on girls' participation in electronics and circuitry projects. Often, we are unaware of the subtle gendered messages that accrue in tools and materials over long histories of use. For example, Lego bricks and robotics are marketed to and often used by boys. By contrast, crafting kits and fabrics are marketed to and often used by girls. In this study, we examined the hands-on learning activities of middle school-aged youth in mixed gender dyads to better illuminate how e-textiles are taken up and how their use is 
negotiated between girls and boys. Data were collected during an elective, 2-week summer workshop with more than 80 youth from the Chicago Public Schools during youth's creative production with e-textiles during workshops taught by leading educators from the National Writing Project. In phase 1, general patterns of practices and participation related to gender were identified in two mixed gender dyads. Data analysis using Mediated Discourse Analysis (MDA) (Scollon, 2001) revealed that while all four youth showed a high level of interest and engagement in e-textiles, girls in both dyads took on leadership roles, planned highly technical aspects of the activities, iteratively problem-solved, and worked without teacher help and assistance more frequently than their male counterparts. In phase 2, we focused on one dyad using microanalyses to enable a more nuanced portrait of youth's interactions and use of tools. The following research questions guided our work:

1. What are e-textile practices?

2. How do gendered patterns around e-textile practices affect youth's division of labor during making activity?

3. What is the resulting impact on the division of participation patterns when creating e-textiles?

\section{Background}

To examine gender equity in youth's design practices, we foreground the unique merger of crafting and electronics practices in e-textiles projects. In this article, we argue that e-textiles merge sewing and electronics practices, combining two sets of gendered practices and expectations associated with craft and electronic materials. Drawing upon mediated discourse theory, we situate each set of practices and materials in a nexus of 
practice (Scollon, 2001), a set of social practices and artifacts tacitly-shared and valued among members in a cultural group. Each cultural practice-with related tools and materials-carries distinct expectations for who and what constitutes experts and expertise. For example, skillful sewing with needles and fabric signals expertise in crafting or fashion cultures while successful construction of a working circuit signals expertise in electrical engineering or STEM learning communities. Additionally, these practices signal femininities and masculinities in gendered communities of practice (Connell \& Messerschmidt, 2005; Paechter, 2003) through histories of sewing (Beaudry, 2006) for girls and electronics for boys (Foster, 1995a/1995b) along with their contemporary traces in expectations for female consumers of craft kits and fashion and for male consumers of video games and robotics.

Theories of mediated discourse (Wertsch, 1991; Scollon, 2001) provide a framework for examining youth's nonverbal handling (Wohlwend, 2009) of needles, conductive thread, batteries, and other mediating tools to uncover the unspoken yet shared gender expectations. Social actors use cultural tools to mediate materials in the environment, shaping and reshaping artifacts and materials in ways that also mediate selves, tools, and the surrounding cultures, including gendered patterns of participation. Actions materialize unspoken agreements that influence who holds the tools, who carries out each step in the design, and eventually what the final product becomes. The youth who holds the tool gets the final "say" —or rather, the deciding mediated action (Wertsch, 1991) - that puts design decisions into effect and thus controls the emerging design. In this way mediated actions hold the key to understanding how unexamined assumptions about who should handle particular tools affect not only the immediate design but the equitable 
distribution of opportunities to participate and to learn.

To reveal how cultural expectations materialize as mediated actions and authorize particular tool uses and tool users, we use a form of MDA that blends Vygotsky's (1935/1978) cultural-historical theory with Bourdieu's theory (1977) of social practice.. Scollon (2001) developed MDA as an action-oriented approach to understand how a toddler learns the cultural expectations and various social practices attached to the nonverbal physical action of handing an object to another person. For example, handing money to a cashier carries a different meaning than handing a birthday present to a friend. Shared understanding of each handing action is an automatic and unspoken agreement to participate in an interaction, with meanings decided nonverbally between the giver and the receiver based on their common knowledge of the histories of surrounding cultural context and their anticipated roles in a cooperative practice. In the e-textiles workshop, an outstretched hand is read as a request for a turn to use materials and can elicit automatic cooperation from others such as handing over the needle and fabric through the participants' prior knowledge of turn-taking routines in school. In this article, we examine children's handing and turn-taking practices with e-textile tools to examine the interplay of electronics materials and gendered expectations for participation.

Tools and materials bear traces of their histories of cultural use and access, communicating gendered scripts that invite participants to perform masculinities and femininities in socially recognized ways (Butler, 1990). Sharing, sewing, or constructing practices become routines, creating dense intersections or nexus of practice (Scollon, 2001) of unspoken yet naturalized ways of "doing and being" — and as we argue here, making - that contribute to differential participation for girls and boys. Important to this 
analysis, e-textile maker cultures merge two sets of implicitly-gendered practices and expectations for uses of needles, fabric, and circuit testing equipment. For example, crafting practices are situated in histories of art, fashion, and design aesthetics that value creative and attractive constructions while electronics practices are situated in histories of STEM education and electronic engineering that value effective and efficient solutions. Sewing practices index femininities enacted in fashion communities of practice and electronics practices index masculinities enacted in engineering communities of practice (Connell \& Messerschmidt, 2005; Paechter, 2003).

Femininities and masculinities can be conceptualized within mediated discourse theory as tacit, idealized, and normalizing ways of doing gender by talking, speaking, playing, sewing, crafting, building, and so on. Youth learn to "do girl" through membership in multiple, overlapping communities of feminine practice (Paetcher, 2003) in which other girls and women model expected social practices. Similar relationships and practices develop among masculinity and masculinities through communities of masculine practice. Following Paechter (2006), we use femininities to refer to girls' and women's practices and performances and masculinities to refer to boys' and men's practices and performances, although such distinctions blur within and across overlapping gendered nexus of practice. Multiple femininities co-exist in relation to one another and in relation to multiple masculinities, overlapping as well with nexus of schooling, childhoods, and so on. We examine tools here to see how they might mediate typical gendered patterns of technology access; however we want to make clear that tools suggest but do not determine practice. Social actors moving among multiple nexus often wield tools in ways that blur or bend expectations to fit their own social purposes and circumstances in a particular moment. 


\section{Methodology}

\section{Research Context \& Participants}

Data were collected during an elective, 2-week summer design workshop with more than 80 middle school youth from the Chicago Public Schools (51\% male, 49\% female; 47\% Black/African-American, 15\% White/European-American, 9\% Hispanic, 9\% Biracial, and $19 \%$ declined to state). Over the course of the two weeks, all youth participated in at least one week of e-textile production as well as one week of game design or digital storytelling. This article focuses on the e-textile workshop conducted during Week 1 as youth created an electronic hand puppet, one of two e-textiles projects. During daily four-hour workshops during the first week, teachers led instruction while youth created working circuitry using the e-textile components and tools (e.g., batteries, conductive thread, LEDs, multimeter).

\section{Data Sources}

Data collected included video and audio recordings, high quality photographs, surveys, and interviews. A wide-angle video camera captured whole-class lessons and the general flow of youth in the classroom. Additional cameras captured close-up footage of focal youth's handling of tools and materials while wireless microphones recorded localized conversations. Four focal youth were randomly chosen by the research team on Day 1. On Day 3, youth selected partners for the e-puppetry project; two focal youth chose to work in mixed-gender dyads that enabled study of gendered access to tools and materials. Each step of each dyad's e-puppetry project was documented using still photographs or screen captures. Surveys and interviews documented youth's previous crafting and electronics experiences. 


\section{Data Analysis}

We examined mediated actions in crafting and electronics practices to track how gendered practices affected the distribution of labor in e-textile projects and to identify those mediated actions that might rupture the typical nexus and enable new participation patterns to emerge.. The first hour of e-puppetry work was selected as representing a critical segment of time when dyads established patterns of negotiation and participation as well as dealt with complex problem solving tasks in relation to electronics and crafting. The e-puppetry project was especially complex given the collaborative challenge of creating two interactive sock puppets that each contained half of the circuit, that is, one puppet contained the battery while the other contained the $\operatorname{LED}(\mathrm{s})$. When the puppets were joined at a specific point, the circuit was completed and the LED(s) lit up. This proved to be a complex design task for all of the youth involved in the workshop.

This hour of video data was analyzed and coded for the handling of tools and materials to see how e-textile tools shape participation patterns. MDA of videotaped activity located the crafting and electronics practices that occurred most frequently for both focal pairs of youth.The frequency of a set of observed practices is an indicator of its shared acceptance as commonplace and tacit among participants. Using StudioCode, we identified instances of high-frequency practices in videotaped activity. To derive frequency counts for coding purposes, an instance consisted of a strip of video from the moment one youth picked up a tool or material and started using it to the moment when that youth stopped using the object or switched to a new practice (e.g., from sewing to testing a circuit). Each mediated action was coded and categorized as a crafting and/or electronics 
practice. Frequency and duration of use were calculated for tools and key practices to compare youth's access to the project.

Through this coding process, we identified rich moments in the data when youth in the focal dyad used crafting and electronics practices in the course of making the epuppetry project. In these key moments, we coded for markers of engagement and collaboration during youth's interactions. Related talk was coded as one indication of youth's engagement and leadership in the project, but we also analyzed the negotiation of access and maintenance of control by closely examining actions through nonverbal modes:

- gestures such as an outstretched open hand or a reaching attempt,

- positioning of project in relation to dyad

- gazing or refusing to recognize a gaze, or

- posture that turns away and closes off access.

Through close analysis of three key but representative moments, we analyzed who handled which e-textile tools and materials to track gendered patterns in youth's making and participation.

\section{Findings}

When examining broader patterns in the data related to the research questions, we drew from data across the two dyads. Based on frequency and duration for each practice in the first hour of the e-puppetry project, we identified two key groupings of practices that youth used to mediate (e.g., alter materials to construct a puppet or make a working circuit) electronic puppets (see Table 1). The first key grouping included crafting practices: threading the needle, tying a knot, stitching, and gluing. These crafting e-textile practices index historically feminized practices and gendered communities, evident as girls in both 
dyads engaged in sewing and crafting practices 80 percent of the time compared to their male partners' 20 percent (see Table 1). In other words, when there was stitching, knotting, threading, or gluing to be done, the female member of the dyad was far more likely to engage in the practice than her male counterpart. In e-textile work, stitching is not simply decorative or structural, but sewing is the way that the current passes through the embedded circuit from the battery to the LED—sewing creates the circuit.

The second key grouping included electronics practices. These practices all involved using the multimeter-a common and low-cost handheld device used by electricians to test for conductivity (a material's ability to conduct electricity or carry electronic current) as well as measure electric current and voltage. All youth learned to use multimeters during the first two days of the workshop. However, multimeters index historically masculinized practices in STEM and electronics fields. The dyads engaged in electronics practices far less frequently than crafting practices, but when the multimeter was used, boys had the equipment in their hands 75 percent of the time on average to only 25 percent for girls (see Table 1). These electronics practices were especially common when the dyads problemsolved a design issue. For example, the dyads routinely used the multimeter to check the battery holder to test or ensure continuity or electrical flow. In other words, the multimeter allowed youth to confirm whether electricity was flowing from the positive and negative side of the battery through the conductive material and/or conductive thread to other parts of the circuit. Periodically using the multimeter allowed youth to check each step of the process rather than finding mistakes at the end and redoing large sections of circuitry. Table 1: Identifying Key Practices Within Mixed-Gender Dyads

\begin{tabular}{|l|c|c|}
\hline & $\begin{array}{c}\text { Average percentage } \\
\text { of time GIRLS engaged }\end{array}$ & $\begin{array}{c}\text { Average percentage } \\
\text { of time BOYS engaged }\end{array}$ \\
\hline
\end{tabular}




\begin{tabular}{|l|c|c|}
\hline Key Practices \& Description & in key practices & in key practices \\
\hline $\begin{array}{l}\text { Crafting Practices } \\
\text { Threading the needle, sewing, } \\
\text { gluing, affixing, and making knots }\end{array}$ & $\underline{80 \%}$ & $20 \%$ \\
\hline $\begin{array}{l}\text { Electronics Practices } \\
\text { Testing the electronics for } \\
\text { continuity and determining } \\
\text { conductivity using the multimeter }\end{array}$ & $25 \%$ & $\underline{75 \%}$ \\
\hline $\begin{array}{l}\text { Total percentage of time } \\
\text { engaged in any key practice }\end{array}$ & $\underline{74 \%}$ & $26 \%$ \\
\hline
\end{tabular}

Overall, girls engaged in key e-textile practices for much longer percentages of time (74 percent of the time) than boys ( 26 percent of the time), suggesting that girls actively engaged in the e-textile work. Since girls took up key practices more often, they maintained significant control over the project materials and made more decisions over time. Even though the project required two puppets, the complexity of the design task caused each dyad to focus on one e-puppet at a time. Girls then held or kept the e-puppet in front of them over 80 percent of the time while boys actively watched. Despite boys' inability to get their hands on the project, they remained highly engaged in the e-textile work as evidenced by their talk, gaze, and body position. For example, youth's related talk about the project was nearly even (boys 42 percent; girls 58 percent), suggesting that boys actively worked with their female partners to discuss next steps and verbally problem solve issues that came up. Boys' body positions in both dyads also revealed that while the boys stood or sat to the side of the project, they were leaning in, gazing directly at the project the vast majority of the time. Interestingly, boys exhibited more help-seeking behaviors (asking a peer or a teacher) than girls (boys 61 percent; girls 39 percent). 
In the following section, we illustrate these e-textile gender trends with vignettes of e-puppet-making and closer analyses drawn from one dyad-Amber and Antoine (see Figure 1).

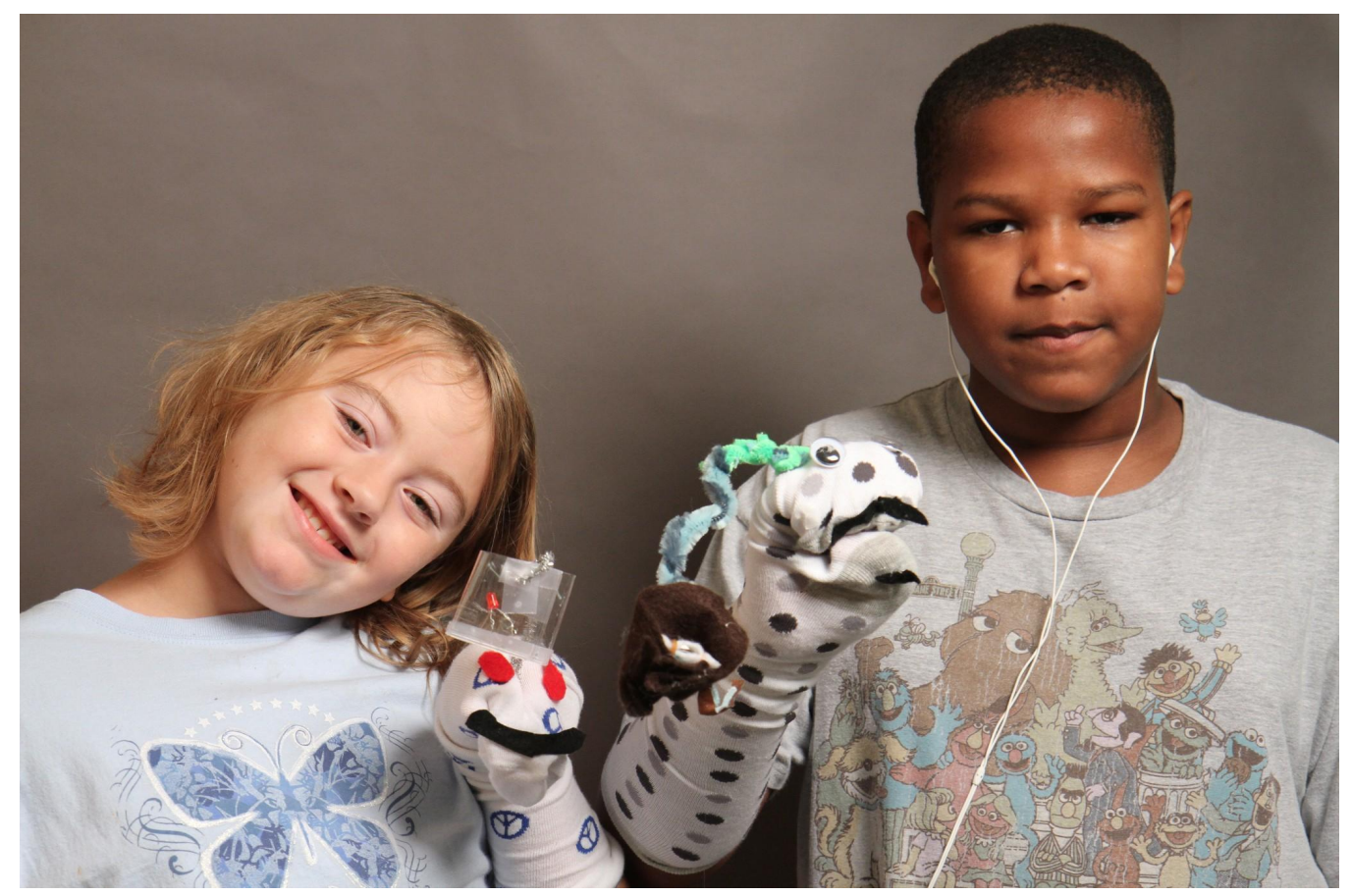

Figure 1: Amber and Antoine model their final e-puppets.

\section{Participants in One Mixed-Gender Dyad}

Amber, a $7^{\text {th }}$ grader, was upbeat and positive, attacking problems with a sense of independence. She had a wide range of interests including computing and crafting with Photoshop and Minecraft. Amber's crafting interests also included paper dolls, scrapbooking, knitting, and jewelry making. She had some limited exposure to sewing because her grandmother was a costume designer for a nearby theater. Although Amber enjoyed sewing (and crafting), she expressed frustration with her novice sewing ability as well as the final products that "usually turn out very crummy." Her family experiences and 
histories developed Amber's interest in crafting, but she explained that her favorite time to work on projects (digital and physical) was after everyone else had gone to bed: "I usually do it late at night during the school year because that is the quietest part of the day-then my brother isn't bugging me and my mom isn't bugging me and my dad isn't bugging me and my homework is done."

Antoine, a $6^{\text {th }}$ grader with an infectious smile, was a serious student but also enjoyed interacting socially with his peers by sharing funny stories and discussing music. Antoine's previous crafting experiences involved woodworking, model building, and sewing. (Antoine's interviews indicated that he had more experience and higher confidence in sewing skills than Amber.) He readily shared stories about working in the garage with his father on woodworking projects, such as a bench for Antoine's football team. It was during this project that Antoine learned how to use the "backside of a hammer when I made a mistake." The deeply social nature of Antoine's histories in these areas was evident in his favorite project: a family gathering at his great-grandmother's house to "pull up the carpet, remove moldings, and sand the floors."

\section{The e-Puppet: A “Simple” Circuit Construction Process}

To situate the dyad's e-textile practices, we describe the construction steps in the first hour of the e-puppet project. Amber and Antoine's process here involved creating two main components of the e-puppet's circuit construction: 1) the battery holder (28 minutes) and 2) a switch (29 minutes). After collecting the necessary materials (3 minutes), the first major challenge for the dyad was to create a working battery holder. The battery used in this project was a coin cell (3V) battery, which was a bit smaller than a nickel (with one 
side positive, the other negative) and typically used to power a watch or other small electronic device. The battery holder constructed by the dyad kept the battery in place while insulating the battery (to prevent it from shorting out the circuit) and drawing out the current necessary to power the rest of the circuit and LED. The youth first made a small envelope out of felt where the battery could easily be slipped in and out. Conductive Velcro inserted into both sides of the felt envelope allowed the battery to be connected to and power the rest of the circuit.

During this hour of video footage, youth also designed a switch to turn on/off their puppet's LED. A switch is any opening in a circuit. While switches can be prefabricated like those slide switches or push-buttons found on toys, a switch can also be created by removing the batteries or by separating any two points in the circuit. The dyad's original idea was to construct each puppet with pipe cleaner antennae so when the antennae touched the circuit was closed and the LED lit up (acting as a type of switch in the project). However, the colored fuzz on the pipe cleaners insulated the metal wire interior from making strong contact, which made its conductivity unreliable. Instead, Amber and Antoine attached the battery holder to the end of one puppet's antennae and the LED on the end of the other puppet's antennae. The circuit was now closed when the two puppets' antennae touched each other, resulting in the LED lighting up. Separating the antennae created a break in the circuit and the LED turned off.

\section{Three Illustrative Vignettes: Comparing Tool Handling in Crafting and Electronics Practices}


The following vignettes offer a more nuanced look at Amber and Antoine's practices and interactions as they worked to collaboratively construct their e-puppets. The excerpted transcripts and microanalyses highlight e-textile practices as well as how the youth negotiated and controlled access to materials and demonstrated engagement. Three moments were selected as identifying representative moments of the key crafting and electronics practices. Though one dyad is explored here, these are demonstrative of the kinds of interactions and gendered practices seen across the dyads.

Amber's sewing and crafting practices. On the third day of the e-textile workshop, Amber and Antoine began to collaboratively create a pair of interactive sock puppets. They choose two brightly colored socks as well as other materials they would need for constructing the e-puppets. After conferring with a teacher, Amber and Antoine returned to their table to begin working on their battery holder. Without any discussion about who would do what, Amber grabbed the needle, cut a piece of non-conductive thread, and threaded it after multiple attempts (3 minutes). In the following excerpt (see Table 2), Amber was attempting to attach small pieces of conductive Velcro to the felt battery holder. She struggled to push the needle through the thick layers of Velcro and felt. Antoine offered to help (given his more extensive experiences sewing), but Amber was reluctant to hand over the project. Instead, she handed him the needle while she maintained control of creating the battery holder. Amber and Antoine's interactions and talk observed during these initial challenges set the scene for their work together over the first hour. 
Table 2: Dyad's Interactions During Amber's Initial Attempt at Sewing

\begin{tabular}{|c|c|c|c|}
\hline Turn & Talk & Mediated Action & Negotiation of Control of the Project \\
\hline 1 & $\begin{array}{l}\text { Antoine: I'm just going to take a wild } \\
\text { guess here: you can't really sew, can } \\
\text { you? }\end{array}$ & & \\
\hline 2 & $\begin{array}{l}\text { Amber: Not really that well, but I can } \\
\text { sew. I know how to at least. Go get } \\
\text { me a different needle. Hurry! l'm not } \\
\text { going to be able to get this one } \\
\text { through. This needle is not going to } \\
\text { work. }\end{array}$ & $\begin{array}{l}\text { Amber tries to thread } \\
\text { needle; licks end of the } \\
\text { non-conductive thread. }\end{array}$ & $\begin{array}{l}\text { Amber is the first to pick up the } \\
\text { needle. When she becomes } \\
\text { frustrated, she sends Antoine to the } \\
\text { supply table to get a "bigger" needle. } \\
\text { Antoine follows Amber's command } \\
\text { without argument. }\end{array}$ \\
\hline 3 & $\begin{array}{l}\text { Antoine: This needle looks a little bit } \\
\text { bigger. }\end{array}$ & $\begin{array}{l}\text { Amber sits at the table, } \\
\text { continuing to try and } \\
\text { thread the needle. } \\
\text { Antoine walks up to the } \\
\text { supply table and } \\
\text { returns with a new } \\
\text { needle. }\end{array}$ & \\
\hline 4 & $\begin{array}{l}\text { Amber: Did I get it? Yeah, I got it. } \\
\text { Ok, wait. Make a small knot. I don't } \\
\text { know how to finish it. }\end{array}$ & $\begin{array}{l}\text { Amber attempts to } \\
\text { thread the new needle; } \\
\text { needle falls on ground. }\end{array}$ & \\
\hline 5 & $\begin{array}{l}\text { Antoine: I know how to make a knot. } \\
\text { Maybe we should have just hot glued } \\
\text { it. }\end{array}$ & & $\begin{array}{l}\text { Antoine implicitly makes a bid to get } \\
\text { his hands on the project by stating } \\
\text { that he knows how to tie knots. } \\
\text { Antoine also implicitly questions } \\
\text { Amber's sewing abilities by making a } \\
\text { bid to use the hot gun instead. }\end{array}$ \\
\hline 6 & $\begin{array}{l}\text { Amber: No, it's fine. I can sew well } \\
\text { enough. This project won't be a bust } \\
\text { if I mess up a little... yeah ... the most } \\
\text { crucial part... I need you to go back, } \\
\text { you little needle. Maybe I should put } \\
\text { this one [needle] through again. } \\
\text { Yeah, that will work. }\end{array}$ & $\begin{array}{l}\text { Amber attempts to } \\
\text { thread needle and gets } \\
\text { needle threaded. }\end{array}$ & $\begin{array}{l}\text { Amber explicitly rejects Antoine's bid } \\
\text { to use hot glue. She also rejects his } \\
\text { implicit bid to pass him the project. }\end{array}$ \\
\hline 7 & $\begin{array}{l}\text { Antoine: Ok, there's the little needle. } \\
\text { We could have taped it. Did you stab } \\
\text { yourself already? Because your finger } \\
\text { is red. }\end{array}$ & & $\begin{array}{l}\text { Antoine shows concern for his } \\
\text { partner's well-being. }\end{array}$ \\
\hline 8 & $\begin{array}{l}\text { Amber: My fingers are always red. I } \\
\text { can't get it after that. }\end{array}$ & Amber licks thumb. & $\begin{array}{l}\text { Amber rejects Antoine's show of } \\
\text { concern. }\end{array}$ \\
\hline
\end{tabular}




\begin{tabular}{|l|l|l|l|}
\hline 9 & Antoine: Let me see it. & $\begin{array}{l}\text { Amber hands needle to } \\
\text { Antoine but continues } \\
\text { to hold fabric. He pulls } \\
\text { on needle to get it } \\
\text { through the fabric. }\end{array}$ & $\begin{array}{l}\text { Antoine explicitly demands to "see" } \\
\text { the project (implicit request to hand } \\
\text { the project to him). }\end{array}$ \\
\hline 10 & $\begin{array}{l}\text { Amber: It's almost out too. Ahh! I } \\
\text { can't get it after that. }\end{array}$ & $\begin{array}{l}\text { Amber pulls but can't } \\
\text { get needle out. Antoine } \\
\text { pulls out needle. }\end{array}$ & $\begin{array}{l}\text { Amber ignores Antoine's demand to } \\
\text { see the project. }\end{array}$ \\
\hline 11 & $\begin{array}{l}\text { Antoine: We can start over on a new } \\
\text { piece. Let's try hot glue, sewing isn't } \\
\text { going so well. }\end{array}$ & $\begin{array}{l}\text { Amber: Yeah, lets take out the } \\
\text { thread. Let's tell 'em we need glue. }\end{array}$ & $\begin{array}{l}\text { Antoine makes a bid to start the } \\
\text { project over with new materials; } \\
\text { repeats suggestion to change tools }\end{array}$ \\
\hline 12 & $\begin{array}{l}\text { Antoine: You know we could just get } \\
\text { a whole new piece of fabric. }\end{array}$ & $\begin{array}{l}\text { Amber accepts Antoine's bid to use } \\
\text { the glue gun instead of sewing. }\end{array}$ \\
\hline 13 & $\begin{array}{l}\text { Amber: It's fine. I just have to take } \\
\text { out the thread. }\end{array}$ & $\begin{array}{l}\text { Amber cuts off thread } \\
\text { with needle attached } \\
\text { thread from the fabric. }\end{array}$ & $\begin{array}{l}\text { Amber rejects Antoine's bid and } \\
\text { states that she'll just remove the } \\
\text { thread. }\end{array}$ \\
\hline project over with new materials.
\end{tabular}

Amber exhibited overt confidence and leadership as she initially ignored and explicitly rejected Antoine's bids to use the glue gun (e.g., Table 2, Turn 6: “No it's fine."). While Antoine's gaze, body language, actions, and talk indicate that he was engaged in moving the project forward, Amber maintained physical control of the project during the entire four-minute episode. Amber's talk positioned Antoine as an assistant to whom she can give directives (e.g., Table 2, Turn 2: “Go get me a different needle."). There were multiple moments of difficulty when Amber could have handed off the project to Antoine (or a teacher), but she appeared convinced that even though she was not an experienced seamstress, she knew enough about sewing to figure it out on her own.

Antoine's sewing and crafting practices. After nearly an hour of work on the 
project, Amber and Antoine finished constructing the main elements of the battery holder. The dyad's battery holder consisted of a felt envelope with conductive Velcro inserted into both sides. The conductive Velcro was accessible through small holes cut on each side of the holder. The dyad had attached skinny strips of conductive material to the holder in such a way that the strips touched the conductive Velcro pads. This design resulted in the current flowing from the positive and negative side of the battery through the conductive Velcro on each side and then out to the conductive strips of fabric. While this design worked electronically, the dyad found that the strips were far too short to reach from the battery on one puppet to the LED on the other puppet. Amber decided they would extend the length of the strips by sewing additional strips of conductive material onto each.

Amber and Antoine's initial attempts with sewing were frustrating (see Table 2) until a teacher demonstrated how to sew because other dyads warned that hot glue insulated the conductive materials and prevented the circuit from functioning. This risk and demonstration how to sew encouraged the pair to return to the needle and sew again (see Table 3). Amber finished successfully threading the needle, and was working to tie a knot at the end of the thread when Antoine offered to help (see Table 3, Turn 1). Antoine had demonstrated his ability to tie knots earlier, so here she handed over the project without argument. By allowing Antoine to tie a knot, Amber permitted Antoine to be involved in the project without giving up much control. The practice of tying a knot is time bound and offers little room for extraneous decision-making. Of the few times Antoine was identified as engaging in a crafting practices during the e-puppetry project, Amber routinely kept one hand on the project and/or closely monitored his work. 
Table 3: Dyad's Interactions During one of Antoine's Attempts at Sewing

\begin{tabular}{|c|c|c|c|}
\hline Turn & Talk & Mediated Action & Negotiation of Control of the Project \\
\hline 1 & $\begin{array}{l}\text { Antoine: You know I could have just } \\
\text { tied the knot. }\end{array}$ & & $\begin{array}{l}\text { Antoine continues to show engagement by } \\
\text { suggesting that he "could have just tied the } \\
\text { knot." (despite rarely handling the project } \\
\text { or tools) }\end{array}$ \\
\hline 2 & $\begin{array}{l}\text { Amber: You tie the knot. Wait! Make } \\
\text { it tight, all the way tight (begins } \\
\text { humming a song). I love these } \\
\text { pincushions. They make things a } \\
\text { heck of a lot easier so you don't have } \\
\text { to hold the needle and do what Ms. } \\
\text { Bell showed us. I'm going to cut } \\
\text { these little pieces (of conductive } \\
\text { material) in half because we have a } \\
\text { little bit too much. Hurry dude! }\end{array}$ & $\begin{array}{l}\text { Amber hands threaded } \\
\text { needle to Antoine. } \\
\text { Antoine working to tie } \\
\text { multiple knots at end of } \\
\text { thread. } \\
\text { Amber plays with } \\
\text { pincushion and then } \\
\text { cuts strips of conductive } \\
\text { fabric in half to make } \\
\text { them smaller. }\end{array}$ & $\begin{array}{l}\text { While Amber's gaze moves away from } \\
\text { Antoine's knot tying efforts, she verbally } \\
\text { checks in with Antoine multiple times about } \\
\text { his progress ("Hurry dude!") (turns \# } 2 \text {, \#4, } \\
\# 7 \text { ). }\end{array}$ \\
\hline 3 & $\begin{array}{l}\text { Antoine: Wait! Wait! The knot needs } \\
\text { to be a little bit bigger. Double } \\
\text { knotted. }\end{array}$ & & $\begin{array}{l}\text { Antoine bids to have more time with the } \\
\text { project so he can make sure the knot is } \\
\text { large enough. }\end{array}$ \\
\hline 4 & $\begin{array}{l}\text { Amber: Double, triple, quadruple } \\
\text { knot. Dude we are sewing through } \\
\text { conductive fabric. }\end{array}$ & & $\begin{array}{l}\text { Amber reaffirms Antoine's bid to tie more } \\
\text { than one knot. }\end{array}$ \\
\hline 5 & Teacher: Does anyone need help? & & $\begin{array}{l}\text { Antoine and Amber offer completely } \\
\text { different responses to the teacher's inquiry } \\
\text { into how the pair is doing. Antoine states } \\
\text { that the pair needs help with "everything" } \\
\text { (Turn 6) while Amber states the pair is } \\
\text { "good" (Turn 9). }\end{array}$ \\
\hline 6 & Antoine: We do with everything. & $\begin{array}{l}\text { Antoine tying knots at } \\
\text { end of thread. } \\
\text { Amber begins trying to } \\
\text { push the needle through } \\
\text { the edge of the battery } \\
\text { holder as Antoine } \\
\text { finishes making knots at } \\
\text { the end. }\end{array}$ & $\begin{array}{l}\text { Amber appears eager to gain back control } \\
\text { of the project right after Antoine states that } \\
\text { they "need help with everything." Even } \\
\text { though Antoine's not finished knotting, } \\
\text { Amber picks up the needle and begins } \\
\text { trying to push the needle through the } \\
\text { fabric. Amber works to avoid a detour in } \\
\text { the project. }\end{array}$ \\
\hline 7 & $\begin{array}{l}\text { Amber: Hurry Nicholas! I think that is } \\
\text { good, that's good enough. }\end{array}$ & $\begin{array}{l}\text { Antoine tying knots at } \\
\text { end of thread. }\end{array}$ & $\begin{array}{l}\text { Amber pushes Antoine to finish tying knots } \\
\text { so she can move forward with the project. }\end{array}$ \\
\hline 8 & Teacher: How you all doing? & Antoine tying knots in & \\
\hline
\end{tabular}




\begin{tabular}{|c|c|c|c|}
\hline & & thread. & \\
\hline 9 & Amber: Good. & $\begin{array}{l}\text { Amber's gaze moves to } \\
\text { the teacher for one } \\
\text { second and then gaze } \\
\text { returns to project. } \\
\text { Amber tries to pull the } \\
\text { needle through the } \\
\text { fabric while Antoine } \\
\text { continues to knot the } \\
\text { end. }\end{array}$ & \\
\hline 10 & $\begin{array}{l}\text { Teacher: Are you all excited? Can't } \\
\text { wait to see. Once you get your circuit } \\
\text { built with your switch you'll be able to } \\
\text { decorate them, and that's the fun } \\
\text { part. }\end{array}$ & $\begin{array}{l}\text { Neither Amber nor } \\
\text { Antoine looks at } \\
\text { teacher. Both youth } \\
\text { continue to gaze at } \\
\text { project. Amber tries to } \\
\text { pull the needle through } \\
\text { the fabric while Antoine } \\
\text { continues to knot the } \\
\text { end. }\end{array}$ & \\
\hline 11 & Amber: Uh-huh. & $\begin{array}{l}\text { Amber tries to pull the } \\
\text { needle through fabric. }\end{array}$ & $\begin{array}{l}\text { Amber does not engage in conversation } \\
\text { with teacher. She offers short responses } \\
\text { aimed at getting teacher to leave the pair } \\
\text { alone. }\end{array}$ \\
\hline 12 & $\begin{array}{l}\text { Antoine: Okay, try it. Try to pull it } \\
\text { through. I'm going to let you handle } \\
\text { the sewing part. I use to, I could sew } \\
\text { but I don't do it anymore. }\end{array}$ & $\begin{array}{l}\text { Antoine is finished tying } \\
\text { knots; drops the thread. } \\
\text { Amber tries to pull } \\
\text { needle through the } \\
\text { fabric. }\end{array}$ & $\begin{array}{l}\text { Amber regains sole control of the project } \\
\text { now that Antoine has finished tying knots. }\end{array}$ \\
\hline
\end{tabular}

Amber offered Antoine a fair amount of independence (1 minute) to tie a knot until Antoine told the teacher that they needed help with everything (see Table 3, Turn 6). It was at this point that Amber was eager to gain back control of the project right. Picking up the needle as Antoine was still tying knots suggests that Amber was eager to move forward with the project and was perhaps apprehensive that Antoine would hand off the project to the teacher. By picking up the needle Amber resumed at least partial control of the project and had more power to determine whether the project was handed off to a teacher. (This reflects the general pattern discussed earlier that boys in the dyads were more likely to 
seek help than girls). Amber was confident that the pair could proceed without help from the teacher; Antoine, though, was not so sure.

The dyad's collaborative and contested electronics practices. Just as Amber and Antoine finished gluing strips of conductive fabric onto the positive and negative sides of battery holder, positioned in such a way that they made contact with the conductive Velcro inside the holder through small holes, the teachers reminded the class to frequently "test" to see if the battery holders were actually working. Although Amber was first to suggest that they needed to test the battery holder, Antoine didn't hesitate to take control at this point and picked up the multimeter to test the battery holder (see Table 4). He began by testing the conductivity of the fabric strips they just finished (30 seconds). The multimeter indicated that the strips remained conductive and were functional parts of the battery holder. Next, Antoine used the multimeter to check the flow of electricity (i.e., continuity) from the battery to the conductive fabric strips. He does not get the reading he expected on the multimeter, and Amber grew impatient; she reached in to grab control of the multimeter and adjusted it herself. 
Table 4: Dyad's Interactions Over the Use of the Multimeter

\begin{tabular}{|c|c|c|c|}
\hline Turn & Talk & Mediated Action & Negotiation of Control of the Project \\
\hline 1 & $\begin{array}{l}\text { Amber: Okay, now } \\
\text { we've got to test this. }\end{array}$ & $\begin{array}{l}\text { Amber and Antoine finish gluing and } \\
\text { begin walking back to their table. }\end{array}$ & $\begin{array}{l}\text { Amber makes a bid to check the battery } \\
\text { holder after gluing the strips of } \\
\text { conductive fabric. Other pairs of students } \\
\text { have discovered that glue can block the } \\
\text { continuity of the current. }\end{array}$ \\
\hline 2 & $\begin{array}{l}\text { Teacher: Hey bring } \\
\text { yours here and let's } \\
\text { check the voltage. } \\
\text { Now everybody look, } \\
\text { because I was testing } \\
\text { that wrong a while } \\
\text { ago. When you get } \\
\text { your battery case } \\
\text { made and you have } \\
\text { your battery and you } \\
\text { want to test it, you } \\
\text { turn it [the multimeter] } \\
\text { to } 20 \text { volts and touch } \\
\text { the negative side and } \\
\text { the positive side and } \\
\text { READ what it says. It } \\
\text { should be right at } 3 \\
\text { volts. }\end{array}$ & $\begin{array}{l}\text { Amber and Antoine go stand near the } \\
\text { teacher as she explains how to test the } \\
\text { battery holder. The teacher uses their } \\
\text { battery holder to point out where to } \\
\text { connect multimeter, but she does not } \\
\text { actually test it for them. } \\
\text { Antoine and Amber walk back to table } \\
\text { where they've been working. }\end{array}$ & \\
\hline 3 & $\begin{array}{l}\text { Antoine: Ours isn't } \\
\text { going to be. Okay, but } \\
\text { first let's see if they } \\
\text { beep. }\end{array}$ & $\begin{array}{l}\text { Antoine and Amber both reach for the } \\
\text { multimeter, but Antoine gets to it first. } \\
\text { He tests the strips of conductive fabric } \\
\text { coming from the positive side first and } \\
\text { then the negative side of the battery. } \\
\text { This multimeter beeps both times } \\
\text { indicating that the fabric is conductive. }\end{array}$ & $\begin{array}{l}\text { Antoine isn't confident that the battery } \\
\text { holder is going to work. Before doing } \\
\text { continuity testing, Antoine wants to do a } \\
\text { quick conductivity test to make sure it's } \\
\text { working and the multimeter successfully } \\
\text { beeps to his surprise. }\end{array}$ \\
\hline 4 & $\begin{array}{l}\text { Amber: Okay, we } \\
\text { need volts. }\end{array}$ & $\begin{array}{l}\text { Antoine turns the multimeter dial to } 20 \\
\text { volts. Amber watches closely. }\end{array}$ & $\begin{array}{l}\text { Amber explicitly bids to move on to } \\
\text { additional testing. }\end{array}$ \\
\hline 5 & Antoine: Twenty volts. & $\begin{array}{l}\text { Antoine attaches the multimeter to the } \\
\text { strips of fabric connected to the battery. } \\
\text { Antoine and Amber's gaze moves back } \\
\text { and forth between project and } \\
\text { multimeter. They don't get the reading } \\
\text { they're expecting. }\end{array}$ & $\begin{array}{l}\text { Antoine accepts Amber's bid and moves } \\
\text { on to conduct additional testing. }\end{array}$ \\
\hline 6 & $\begin{array}{l}\text { Amber: Let me do } \\
\text { this. }\end{array}$ & $\begin{array}{l}\text { Amber reaches in and tries to take the } \\
\text { multimeter out of Antoine's hands. }\end{array}$ & $\begin{array}{l}\text { Amber becomes frustrated and makes a } \\
\text { bid to take over control of the multimeter. }\end{array}$ \\
\hline 7 & $\begin{array}{l}\text { Antoine: Hold on! } \\
\text { Hold on! Put one here } \\
\text { on the positive. Put } \\
\text { one here on the } \\
\text { negative. Put one }\end{array}$ & $\begin{array}{l}\text { Antoine resists giving up the multimeter } \\
\text { at first, but Amber physically pulls it out } \\
\text { of out of his hands. }\end{array}$ & $\begin{array}{l}\text { Antoine initially resists Amber's bid to } \\
\text { take over, but she physically forces him } \\
\text { to let go of the multimeter. He remains } \\
\text { engaged in the project as he gives } \\
\text { instructions for how to get a better }\end{array}$ \\
\hline
\end{tabular}




\begin{tabular}{|c|c|c|c|}
\hline & $\begin{array}{l}\text { needle on the positive } \\
\text { [slight laughter]... }\end{array}$ & $\begin{array}{l}\text { Antoine repeats directions and sounds } \\
\text { frustrated. He points to where he thinks } \\
\text { Amber should connect the multimeter. }\end{array}$ & reading. \\
\hline 8 & $\begin{array}{l}\text { Amber: Hold it } \\
\text { [battery holder] up for } \\
\text { me. }\end{array}$ & $\begin{array}{l}\text { Amber holds the multimeter so she's } \\
\text { unable to hold the battery holder in } \\
\text { place. When prompted, Antoine holds } \\
\text { the battery holder in place and also } \\
\text { helps position the multimeter. The dyad } \\
\text { tries to get a good connection between } \\
\text { the multimeter and the fabric. }\end{array}$ & $\begin{array}{l}\text { Amber explicitly demands that Antoine } \\
\text { hold the battery holder still so that it's } \\
\text { easier for her to attach the multimeter. } \\
\text { Antoine is positioned as an assistant, } \\
\text { again. }\end{array}$ \\
\hline 9 & $\begin{array}{l}\text { Antoine: Twenty- } \\
\text { nine... two point nine. }\end{array}$ & $\begin{array}{l}\text { Amber and Antoine look at dial on } \\
\text { multimeter. }\end{array}$ & \\
\hline 10 & Amber: Is that bad? & $\begin{array}{l}\text { Amber takes her hands off the } \\
\text { multimeter. }\end{array}$ & $\begin{array}{l}\text { Amber asks Antoine to interpret the } \\
\text { multimeter reading. She positions him as } \\
\text { the more knowledgeable participant here } \\
\text { in regards to understanding the } \\
\text { multimeter. }\end{array}$ \\
\hline 11 & Antoine: No. & $\begin{array}{l}\text { Antoine adjusts the multimeter to get a } \\
\text { better reading. }\end{array}$ & $\begin{array}{l}\text { Antoine answers Amber's question with } \\
\text { a clear answer. }\end{array}$ \\
\hline 12 & Amber: It's almost. & $\begin{array}{l}\text { Antoine and Amber go over to a teacher } \\
\text { to confirm that their reading is all right. } \\
\text { Antoine carries multimeter; Amber } \\
\text { carries battery holder. }\end{array}$ & $\begin{array}{l}\text { Interesting that Antoine grabs the } \\
\text { multimeter while Amber takes the } \\
\text { project. This aligns with the frequency } \\
\text { data in terms of who felt more } \\
\text { comfortable with what tools. }\end{array}$ \\
\hline
\end{tabular}

Antoine's eagerness to get his hands on the multimeter provides a stark contrast with the first vignette where it was Amber who grabbed the needle first, despite her admitted lack of sewing skills. The initiative shown by Antoine to physically control the multimeter here is one of the few moments where he attempted to do something to move the project forward without verbally requesting to help or being directed to help. While Antoine controlled the multimeter, Amber kept a close eye on what he was doing and then verbally urged him to move forward with the testing. When the reading on the multimeter does not seem right, Amber moved from a "hands off" observer back into a "hands on" leadership role. She physically contested Antoine's control by reaching in to take the 
multimeter away from him and then directed Antoine to assist (e.g., see Table 5, Turn 6:

"Let me do this."; Table 5, Turn 8: “Hold it [battery holder] up for me."). Interestingly, even though Amber took control of the multimeter, she still deferred questions about the correctness of the reading back to Antoine; he routinely gave unsolicited suggestions about the dyad's next steps in regards to sewing and crafting, but here Amber positioned Antoine as the electronics expert, asking him a direct question that she did not know that answer to (Table 5, Turn 10: "Is that bad?").

\section{Conclusion: Hands on Materials as Gendered Access}

Based on the findings above, we claim that the cultural practices embedded within the e-textiles project offered opportunities for girls to literally take "hands on" leadership roles. This leadership role materialized in the amount of time the project was situated in front of the girls compared to boys. Positionality and handling of the project were critical markers of access as well as leadership. In both dyads, male and female youth were actively engaged in talking about next steps, but it was the girls who, by actively maintaining primary proximity to the project, ensured that they had hands-on access once the next step was verbally decided upon.

When girls took up materials and tools, boys had limited access to and control over the emerging design unless directed by the girls, especially during sewing and crafting practices. Amber allowed Antoine to complete small sewing and crafting tasks (e.g., tying a knot), but she kept a close eye on his work and often kept a hand on the project to ensure that Antoine did not hand it off to a teacher or another peer. In other words, the youth with hands-on access to tools and materials had more control over the next step in the process. 
Specifically, close analysis of mediated actions showed how girls gained and maintained access to electronics equipment and controlled engineering decisions through shared yet unspoken anticipated identities for female crafters embedded in sewing tools and gendered histories of crafting practices. This was true even in the case of Antoine and Amber where the male partner had more experience with sewing. On the other hand, boys typically controlled the electronics practices, a finding which aligns with previous work on electronics and computing fields as male-dominant (e.g., Margolis \& Fisher, 2003).

\section{Discussion}

In contrast to theorizing gender disparities as an inherent "lack" in girls (i.e., girls lack the skills, interest, or confidence necessary to participate equitably with male counterparts), we suggest reconceptualizing this disparity by looking at tacit expectations for cultural practices and social actors that are concretized through historical uses of tools, materials, and gendered communities of practice (Paechter, 2003). Rather than view gender as a static identity marker that defines participation in electronics and computing projects, we found that histories of materials, tools, and practices influenced which member of the dyads was implicitly granted hands-on access. In the case of e-textiles, the replacement of the traditional circuitry toolkit with new materials and tools like needles, fabric, and conductive thread ruptured traditional gender scripts around electronics and computing. In turn, we found that girls took on leadership roles in completing highly complex electronics projects by engaging in practices historically embedded within communities of practice with gendered histories. 
The results from our work highlight the importance of attending to the sociallyconstructed and gendered histories of materials. We found that girls took up sewing and crafting practices more often and for longer periods of time than the male members, and mediated actions that enabled girls to lead and determine the project's next steps. Female youth worked to maintain their hands-on access and control over materials and tools; male youth, on the other hand, were largely "hands off" when paired with female youth but still remained engaged and willing to work on the project as indicated by nonverbal markers in posture, proximity to girl/project, gaze, and talk. This represents a shift in the typical gender dynamics one might observe of youth engaged in robotics activities or other traditionally male-dominated electronic activities involving Legos, circuit boards, and other materials.

Moreover, these cumulative hands-on opportunities are critical to building working knowledge and understanding of electronics and computing concepts over time. All youth certainly can (and did) remain engaged as assistive observers, but gaining hands-on access leads to a deeper level of investment and developing level of competency. As Scollon (2001) theorized, a small change in a mediated action—in this case, handling sewing and crafting tools and materials--resulted in meaningful differences in access, participation, and leadership. In our case, girls' opportunities to get their hands on tools and materials in the e-puppet project had rippling implications for how competently youth performed later in the e-textile workshop. Data collected from these same youth engaged in subsequent etextile projects suggest that girls' access to tools and materials in the e-puppetry project extended beneficial results beyond the successful completion of the puppet. For the second e-textile project, youth worked independently but the ways boys and girls approached the 
project were markedly different. Most noticeable were differences in efficiency (less total completion time) as well as independence (more sustained time working without teacher assistance). At one point in her second e-textile construction, Amber worked for over thirty minutes without adult help, compared to Antoine who never spent more than six minutes working independently. In other words, the gendered access differential in the e-puppetry project appears related to girls needing far less adult support in the following e-textile project. A similar pattern was noted in the second dyad, where the boy took more than twice as long to complete the second e-textile project and required greater teacher intervention.

\section{Implications}

Our research findings, suggest that e-textile toolkits offer female youth expanded access to materials and tools, resulting in opportunities to take on project leadership roles in highly technical STEM areas. To date, however, efforts to draw more female youth into STEM related pathways and experiences have largely revolved around two major efforts: 1) keeping male and female youth/children separated in STEM related classes or clubs (e.g., Khoja, Wainwright, Brosing, Barlow, 2012; Marcu et al., 2010) and 2) encouraging female youth/children to play with "boys'" toys and tools (i.e., toys and tools with masculinized identity markers) (e.g., Clegg, 2001; Hartmann, Wiesner, \& Wiesner-Steiner, 2007; Stepulvage, 2001). The first effort, to keep males and females separated, is exemplified in "girls only day" at the local computer club or same gendered math and science classes in some schools. The assumption is that creating a bounded and protected space for female youth will ensure that females are not intimidated by males who may appear to be more 
confident and competent. The intention is to provide equitable access to tools and materials in mixed gender settings. The second effort is based on children's gendered toy preferences from a very young age. The assumption is that if only girls would take up LEGOs and science kits instead of Barbie dolls and crafting kits, we would not see the stark gender disparities in STEM pathways later; in other words, if girls just played more with boys' toys, gender scripts would change.

Both of these efforts are problematic, positioning girls within a cultural deficit model that either presupposes that girls need to be protected because they are weak and/or that girls need to change to become more like their male counterparts. Our work suggests a new path forward, one that takes a strength orientation to girls and the tools, materials, and practices that have historically been valued in feminine communities of practice. Our findings revealed that gender scripts within electronics and computing are not absolutely fixed, as is assumed in much of the research, but rather that gender scripts are socially situated within tools, materials, and practices. Instead of fixing girls, e-textile materials highlight that existing cultural divides and gender disparities are inscribed on the tools and materials made available to our learners. E-textile toolkits, for example, successfully flip the gendered scripts about who has hands-on access to electronics materials and tools by honoring girls' historic maker practices and, in doing so, expand the ways into complex electronics and computing content. This seemingly small change in the materials and tools produced a rippling effect on the children's classroom practices. Moreover, classrooms, clubs, and afterschool settings need to consider how altering materials and tools may situate STEM practices in cultural contexts that broaden participation patterns and offer youth multiple entry points and opportunities to perform 
identities that are socially valued across communities of practice and their gendered histories. 


\section{References}

Beaudry, M. C. (2006). Findings: The material culture of needlework and sewing. Princeton, NJ: Yale University Press.

Berzowska, J. (2005). Electronic textiles: Wearable computers, reactive fashion, and soft computation. Textile: The Journal of Cloth and Culture, 3(1), 58-75.

Bourdieu, P. (1977). Outline of a theory of practice. Cambridge: Cambridge University Press.

Bryson, M., \& De Castel, S. (1996). Learning to make a difference: Gender, new technologies, and in/equity. Mind, Culture, and Activity, 3(2), 119-135

Buechley, L., Peppler, K. A., Eisenberg, M., \& Kafai, Y. B. (Eds.). (2013). Textile messages: Dispatches from the world of e-textiles and education. New York: Peter Lang.

Buechley, L., \& Mako-Hill, B. (2010). LilyPad in the wild: How hardware's long tail is supporting new engineering and design communities. In Proceedings of the Conference on Designing Interactive Systems (pp. 199-207), ACM Press.

Butler, J. (1990). Gender trouble: Feminism and the subversion of identity. London: Routledge.

Clegg, S. (2001). Theorising the machine: Gender, education and computing. Gender and Education, 13(3), 307-324.

Connell, R. W., \& Messerschmidt, J. W. (2005). Hegemonic masculinity rethinking the concept. Gender \& Society, 19(6), 829-859.

Dougherty, D. (2013). The Maker mindset. In M. Honey, \& D.E. Kanter (Eds.), Design, make, play: Growing the next generation of STEM innovators (pp. 7-11). New York, NY: Routledge.

Foster, P.N. (1995a). Industrial arts/technology education as a social study: The original intent? Journal of Technology Education. 6(2), 4-18.

Foster, P.N. (1995b). The founders of industrial arts in the us. Journal of Technology Education. 7(1), 6-21.

Johnson, S., \& Thomas, A. P. (2010, April). Squishy circuits: a tangible medium for electronics education. In CHI '10 Extended Abstracts on Human Factors in Computing Systems (pp. 4099-4104). ACM. 
Kalil T. (2010). Remarks on innovation, education, and the Maker movement. Retrieved from http://radar.oreilly.com/2010/10/innovation-education-and-the-m.html

Khoja, S., Wainwright, C., Brosing, J., \& Barlow, J. (2012). Changing girls' attitudes towards Computer Science. Journal of Computing Sciences in Colleges, 28(1), 210-216.

Hartmann, S., Wiesner, H., \& Wiesner-Steiner, A. (2007). Robotics and gender: The use of robotics for the empowerment of girls in the classroom. In I. Zorn, S. Maass, E. Rommes, C. Schirmer, H. Schelhowe (Eds.), Gender designs IT: Construction and deconstruction of information society technology (pp. 175-188). Wiesbaden, Germany: VS Verlag für Sozialwissenschaften

Holland, D., \& Cole, M. (1995). Between discourse and schema: Reformulating a culturalhistorical approach to culture and mind. Anthropology \& Education Quarterly, 26(4), 475-489.

Marculescu, D., Marculescu, R., Zamora, N. H., Stanley-Marbell, P., Khosla, P. K., Park, S., Jayaraman, S., Yung, S., Lauterbach, C., Weber, W., Kirstein, T., Cottet, D., Grzyb, J., Troster, G., Jones, M., Martin, T., \& Nakad, Z. (2003). Electronic textiles: A platform for pervasive computing. Proceedings of the IEEE, 91(12), 1995-2018.

Marcu, G., Kaufman, S. J., Lee, J. K., Black, R. W., Dourish, P., Hayes, G. R., \& Richardson, D. J. (2010, March). Design and evaluation of a computer science and engineering course for middle school girls. In Proceedings of the 41st ACM technical symposium on computer science education (pp. 234-238). ACM.

Margolis, J. \& Fisher, A. (2003). Unlocking the clubhouse: Women in computing. Boston, MA: MIT Press.

Paechter, C. (2003). Masculinities and femininities as communities of practice. Women's Studies International Forum, 26, 69-77.

Paechter, C. (2006). Constructing femininity, constructing femininities. In C. Skelton, B. Francis \& L. Smulyan (Eds.), The Sage Handbook of Gender and Education [Electronic version]. London: Sage.

Peppler, K. (2013). STEAM-powered computing education: Using e-textiles to integrate the arts and STEM. Computer, 46(9), 38-43.

Peppler, K., \& Glosson, D. (2013). Stitching circuits: Learning about circuitry through etextile materials. Journal of Science Education and Technology, 22(5), 751-763. 
Pahl, K., \& Rowsell, J. (2006). Travel notes from the New Literacy Studies: Instances of practice. Clevedon, England: Multilingual Matters.

Qi, J. \& Buechley, L. (2010). Electronic popables: Exploring paper-based computing through an interactive pop-up book. In Proceedings of the 4th Conference on Tangible and Embedded Interaction (pp. 121-128). New York, NY: ACM Press.

Scollon, R. (2001). Mediated discourse: The nexus of practice. London: Routledge

Stepulvage, L. (2001). Gender/technology relations: Complicating the gender binary. Gender and Education, 13(3) 325-338.

Vygotsky, L. (1935/1978). Mind in society. Cambridge, MA: Harvard University Press.

Wertsch, J. V. (1991) Voices of the mind: A sociocultural approach to mediated action. Cambridge, MA: Harvard University Press.

The White House. (2009). Remarks by the President on the "Education to Innovate" campaign. [Press release]. Washington, DC: White House Office of the Press Secretary.

Wohlwend, K. E. (2009). Mediated discourse analysis: Researching young children's nonverbal interactions as social practice. Journal of Early Childhood Research, 7(3), 228243. 